\title{
A non-synonymous polymorphism in IL-23R Gene (rs1884444) is associated with reduced risk to schistosomiasis-associated Immune Reconstitution Inflammatory Syndrome in a Kenyan population
}

George O Ogola $a^{1,2}$, Collins Ouma ${ }^{2 *}$, Walter GZO Jura ${ }^{2}$, Erick O Muok ${ }^{1}$, Robert Colebunders ${ }^{3}$ and Pauline N Mwinzi ${ }^{1}$

\begin{abstract}
Background: Human Immunodeficiency Virus (HIV) and Schistosomiasis co-infection is common among residents at the shores of Lake Victoria in Kenya. About 36\% of this population initiating antiretroviral therapy (ART) experience Immune Reconstitution Inflammatory Syndrome (IRIS) that complicates recovery. Several IL-23R alleles have been associated with susceptibility to both autoimmune and inflammatory diseases through T-helper type $17\left(\mathrm{TH}_{17}\right)$ cells. However, whether or not variants within the IL-23R increase susceptibility to IRIS in western Kenya is unknown. The objective of the current study was to determine the association between IL-23R gene polymorphisms, CD4+ cell counts and HIV RNA levels and IRIS in HIV and Schistosoma mansoni co-infected patients undergoing highly active anti-retroviral therapy (HAART).
\end{abstract}

Methods: A three-month case-control study was conducted on antiretroviral naïve schistosomiasis/HIV co-infected fishermen starting HAART in Uyoma Rarieda, Siaya County, Kenya. Seventy one patients were sampled at baseline and followed up for three months, to establish if they developed Schistosoma-related IRIS. In addition, the CD4+ cell counts and HIV RNA levels were determined in pre- and post-administration of HAART. Variations at five polymorphic sites of IL-23R (rs1884444, rs11465754, rs6682925, rs7530511 and rs7539625) based on >10\% minor allele frequency in Yoruban reference population was determined using Allelic Discrimination Assay. The association between the five variants and susceptibility to IRIS was determined using logistic regression while controlling for potential confounders. In addition, the functional differences between the baseline CD4 + Cell counts and viral loads were determined using medians while across IL-23R genotypes were determined using Kruskal-Wallis tests.

Results: Overall, 26 (36.6\%) patients developed schistosomiasis-associated IRIS at a median age of 35.5 years. Carriage of the $\Pi$ genotype at the non-synonymous rs $1884444 \mathrm{~T}>\mathrm{G}$ relative to $\mathrm{GG}$, was associated with a decreased risk of schistosomiasis-associated IRIS (OR, 0.25, 95\% Cl, 0.07-0.96, $P=0.043)$ while both baseline CD4+ cell counts and viral loads had no association with IRIS.

Conclusion: These findings indicate that the non-synonymous variant rs1884444 T>G of IL-23R is associated with a decreased risk to schistosomiasis-associated IRIS. However, additional studies in a larger cohort and with an all inclusive polymorphic variants in the synonymous and non-synonymous regions need to be evaluated.

Keywords: HAART, IRIS, Non-synonymous, SNP, Schistosomiasis

\footnotetext{
* Correspondence: collinouma@yahoo.com

${ }^{2}$ Maseno University, Maseno, Kenya

Full list of author information is available at the end of the article
} 


\section{Background}

Despite the declining incidence of AIDS-related mortality over past decades, it still remains one of the most common causes of death, particularly in sub-Saharan Africa, where resources are limited [1]. A significant number of AIDS cases develop into severe clinical manifestations described as Immune Reconstitution Inflammatory Syndrome (IRIS) during the first few months of starting highly active antiretroviral therapy (HAART) [2-6], leading to additional HIV-related morbidity and mortality. IRIS is characterized by acute inflammatory responses to chronic opportunistic infections such as schistosomias, and is accompanied by a state of immunosuppression, with the immune system beginning to recover with a response to a previously acquired opportunistic infection which results in a heightened inflammatory response that ironically makes the symptoms of infection worse [2,3,7-12]. The condition manifest with a wide range of clinical presentations and is associated with a number of antigenic targets $[13,14]$, including, for example, antigens from viable replicating infective pathogens during a sub-clinical infection (unmasking IRIS), or from dead pathogen debris and dying of non-infective pathogens (paradoxical IRIS), host antigen (autoimmune disease), tumor antigen and other inflammatory conditions [13-15]. The pathogenesis of IRIS is poorly understood, however, monocytes and natural killer (NK) cells involved in innate immunity, inappropriate function of T-cell, polymorphism in human leukocyte antigen (HLA) and cytokine-related genes, have been associated with this clinical condition $[16,17]$.

IL-23R is a type 1 trans-membrane protein found on dendritic cells, monocytes, activated T-cells and NK cells [18]. The IL-23R is a heterodimer, comprising the IL-12R $\beta 1$ and a novel sub-unit named IL-23R [18]. The IL-12R $\beta 1$ and the IL-12R $\beta 2$ sub-units also form the IL-12 receptor (IL-12R). The IL-23R has an extracellular domain made of a signal sequence, an $\mathrm{N}$-terminal immunoglobulin-like domain, and two cytokine receptor domains. The intracellular domain of IL-23R has seven tyrosine residues that can be phosphorylated. Three of the residues are src homology, two are domain-binding sites while two are signal transducers and activators of transcription (STAT) binding sites [19]. Binding of IL-23 to its receptor causes activation of Janus kinases (Jaks) which phosphorylates IL-23R at certain locations, thus forming docking sites for the STATs, and further enabling them to translocate to the nucleus where transcription of pro-inflammatory genes such as IL-17 and interferon- $\gamma$ (IFN- $\gamma$ ) are initiated [19].

IL-23 is responsible for the differentiation and proliferation of $\mathrm{Th}_{17} / \mathrm{Th}_{\mathrm{IL}-17}$ cells from naive $\mathrm{CD}^{+} \mathrm{T}$ cells [20]. $\mathrm{Th}_{17}$ aids in pathogen clearance and tissue inflammation by expressing elevated levels of the pro-inflammatory cytokine (IL-17) in response to stimulation, in addition to IL-1, IL-6, TNF- $\alpha$, IL-22, and IL-25 (IL-17E) [21].
Other studies have also shown that IL-23-deficient mice were resistant to central nervous system's (CNS) autoimmune inflammation because they were unable to develop IL-17 producing $\mathrm{Th}_{\mathrm{IL}-17}$ cells [22]. Genome-Wide Association Studies (GWAS) have also established the IL-23R gene, as the susceptibility locus associated with some chronic inflammatory diseases, such as Crohn's disease, inflammatory bowel disease and psoriasis [23-27], implicating this receptor in inflammatory diseases. However, to date, the functional associations between the IL-23 receptor (IL-23R) variants and susceptibility to Schistosomarelated IRIS in populations resident in Lake Victoria remains unknown. We hypothesized that the genetic variants within the synonymous (point mutations) and non-synonymous (an insertion or deletion of a single nucleotide in the sequence during transcription leading to a frameshift mutation) IL-23R gene would be predisposing factors for susceptibility to Schistosoma-related IRIS. Five polymorphisms were selected based on the frequency of mutant alleles $(>10 \%)$ in the reference African Yoruba population following previous studies that have demonstrated that genes with mutant alleles having high frequencies are likely to be undergoing disease selective pressure $[28,29]$. The hallmark of HIV infection is characterized by depletion of CD4+ T cells and concomitant increase in HIV load [30,31]. IL-23 promotes proliferation of memory $\mathrm{CD} 4+\mathrm{T}$ cells which are preferentially infected by HIV [19,32]. Despite years of intensive research, the mechanisms of CD4+ T cells depletion by the virus has remained widely speculative and it remain unclear whether or not, variation in the IL-23 or its receptor genes, could play a role in IRIS pathogenesis. Our current findings demonstrate that none of the IL-23R variants were associated with changes in CD4+ cells or HIV load during HAART. Results further demonstrated that carriage of the TT genotype at the rs1884444 $\mathrm{T}>\mathrm{G}$ relative to GG, was associated with a decreased risk of schistosomiasis-associated IRIS.

\section{Methods}

\section{Study population}

The study targeted the fishing community in Uyoma, Rarieda District, along the shores of Lake Victoria in Kenya, a group occupationally-exposed to water infested with the infective stage of Schistosoma mansoni parasite. The prevalence of schistosomiasis in this population is high with about a third of them HIV-1 co-infected [33-36].

The following inclusion criteria were employed during recruitment of the study participants: participants had to be $\geq 18$ years of age, be permanent resident of the study area, and willing to sign informed consent form. Other criteria for inclusion were: having undergone voluntary HIV counseling and testing in a recognized government institution, be HAART naive at the beginning of the 
study, must have been screened for and had a history of treated schistosomiasis. Exclusion criteria included presence of other most common co-infections (e.g. malaria, tuberculosis, hepatitis B) in the populations that may independently dysregulate immune responses.

HAART naïve individuals were consented, recruited and underwent parasitological screening for schistosomiasis and Voluntary Testing and Counseling (VCT) for HIV prior to enrollment in HAART (this involved prescription of a combination of three drugs: lamivudine, stavudine and nevirapine) in a health care provider of their own choice.

\section{Ethical considerations}

Prior to initiation of the study, the scientific and ethical clearance was obtained from the Scientific Steering Committee (SSC number 1763) and Ethical Review Committee (ERC), respectively, based at the Kenya Medical Research Institute (KEMRI).

\section{Laboratory testing and evaluations}

Laboratory testing and evaluations were performed at baseline, after one month and three months postenrollment. Schistosomiasis parasitological screen was performed by Kato Katz thick stool smear as previously defined [37]. However, data on HIV load and CD4 cell counts were both collected at baseline and three months post-HAART. The CD4 cell counts were performed using BD TruCount (BD Bioscience, San Jose, California) while HIV loads were determined using Amplicor HIV-1 Monitor Test (version 1.5) (Roche, Basel, Switzerland) from plasma stored at $-80^{\circ} \mathrm{C}$. Malaria parasitemia was determined by microscopy using Giemsa-stained blood smears while tuberculosis was determined using the standard tuberculosis skin test (PPD Skin Test). The Hepatatis B testing was conducted serologically using the Hepatatis B blood panel tests (Core Technology, Beijing, China), as per manufacturer's instructions.

Schistosomiasis-associated IRIS was defined as either the re-emergence of symptoms of otherwise successfully treated schistosomiasis on initiation of HAART or the production of schistosome eggs by individuals who were not producing eggs before initiating HAART [38]. The chronic symptoms of schistosomiasis-associated IRIS included at least three of the following: hepato-splenomegaly; ultra-sound finding or clinical signs of hypertension; ultra-sound finding or clinical signs of increased granuloma formation/liver fibrosis; haematuria; and egg production in stool (whose presence could not be explained by other possible cause). Laboratory and clinical data were obtained at each visit and stored in electronic data base.

\section{Polymorphism genotyping}

Genomic DNA was isolated from $2 \mathrm{~mL}$ of peripheral whole blood using Qi-Amp Midi kit (Qiagen, Hilden, Germany) as per manufactures instructions. A total of 5 polymorphic sites within the IL-23R were selected based on the mutant's allele frequencies of over $10 \%$ in reference African Yoruba population (dbSNP: http://www. ncbi.nlm.nih.gov/SNP/, HAPMAP: http://www.hapmap. org/index.html.en). The IL-23R polymorphisms identified were rs7530511, rs1884444, rs11465754, rs6682925 and rs7539625. The polymorphic variants were determined using TaqMan 5' Allelic Discrimination-Assay-By-Design (Applied Biosystems, Foster City, CA). Briefly, the assays were performed in a total volume of $5 \mu \mathrm{l}$ (containing Taqman Universal Master Mix and SNP Genotyping Assay Mix) with the following amplification protocol: $95^{\circ} \mathrm{C}$ for $10 \mathrm{~min}$, followed by 40 cycles of $95^{\circ} \mathrm{C}$ for $15 \mathrm{sec}$ and $60^{\circ} \mathrm{C}$ for $1 \mathrm{~min}$. Allele-calling was carried out using allele-specific fluorescence on the ABI StepOnePlus real-time PCR system (Applied Biosystems, Foster City, CA, USA). The automated sequence detection software (SDS) was then used for allelic discrimination (Applied Biosystems, Foster City, CA).

\section{Statistical analysis}

Data was analyzed in SPSS (version 17.0 Chicago, IL). Proportions and allele frequencies between IRIS patients and controls were assessed through the use of Pearson $x^{2}$ and Fisher's exact tests while Kruskal-Wallis test was used to analyze differences across groups. Medians were compared using the Mann-Whitney $U$ test. Logistic regression analyses were used to calculate odds ratios (OR), 95\% confidence interval (CI) and corresponding $P$-values for the association of each variant and susceptibility to IRIS, while controlling for the confounding effects of age and sex. These confounders were controlled for based on previous studies which have shown that they independently alter cytokine levels in disease [39]. The dependent variable in the regression analyses was the development of IRIS while the independent variables were the IL-23R genotypes. All $P \leq 0.05$ were considered statistically significant.

\section{Results}

\section{Demographic characteristics of the study participants}

A total of ninety adults $(n=90)$ eligible patients were identified, 19 individuals were excluded from the study due to incomplete laboratory data. Of the remaining 71 study participants, 35 (49.3\%) were males while 36 (50.7\%) were females. A total of $26(36.6 \%)$ of the patients developed IRIS while forty five (63.4\%) did not develop IRIS and were used as controls. The distribution of the males vs. females $(P=0.154)$, median age $(P=0.867)$, baseline CD4 cell counts $(P=0.101)$ and baseline HIV plasma viral 
loads $(P=0.116)$ were comparable between the IRIS and non-IRIS patients. These findings demonstrate that demographic characteristics between the cases and the controls were fairly comparable in the study population (Table 1).

Prevalence of IL-23R genotypes in S. mansoni-infected patients undergoing HAART

Samples from the $71 \mathrm{~S}$. mansoni-infected individuals undergoing HAART were genotyped for the IL-23R polymorphisms (Table 2). Results revealed a comparable distribution of variants within the rs7530511 $(P=0.518)$, rs1884444 $(P=0.091)$, rs11465754 $(P=0.426)$, rs6682925 $(P=0.393)$, and rs6682925 $(P=0.088)$ between the IRIS and non-IRIS patients (Table 2 ).

Association between IL-23R genotypes and susceptibility to S. mansoni-related IRIS

In order to determine the association between IL-23R genotypes and susceptibility to $S$. mansoni-related IRIS, a multivariate logistic regression analyses was carried out while controlling for the confounding effect of age and sex. Results revealed that relative to the GG genotype, carriage of the TT genotype at the rs1884444 locus was associated with a reduced risk to IRIS (OR: 0.25, 95\% CI: $0.07-0.96, P=0.043)$. However, none of the other variants were associated with susceptibility to IRIS (Table 3 ).

The functional role of rs7530511, rs1884444, rs11465754, rs6682925, rs7539625 and changes in CD4 cell counts and HIV loads in blood

In order to determine the functional role of IL-23R variants in conditioning CD4 cell counts and HIV loads, the medians in cases versus controls were compared using Mann-Whitney U test, while across genotype comparisons was determined using Kruskal-Wallis test. Results in all the IL-23R variants demonstrated a marked decrease in HIV load coupled with marked improvement in CD4 cell counts. Additional across group comparison in genotypes revealed comparable levels in CD4 cell counts and HIV viral loads for variants in rs7530511 $(P=0.500, P=0.405)$, rs1884444 $(P=0.414, P=0.648), \operatorname{rs} 11465754(P=0.782$, $P=0.975)$, rs6682925 $(P=0.700, P=0.818)$, and rs7539625

Table 1 Demographic characteristics of the study participants

\begin{tabular}{llll}
\hline & IRIS & NON-IRIS & P-value \\
\hline Age at enrolment, years & $35.5(28-45)$ & $34(29-41)$ & $0.867^{\mathrm{a}}$ \\
Male (n) (\%) & $14(53.8)$ & $21(46.7)$ & $0.154^{\mathrm{b}}$ \\
Base-line CD4 count & $171.5(112-251)$ & $216(144-317)$ & $0.101^{\mathrm{a}}$ \\
Base-line Viral Load & $93.2(9.8-213)$ & $234(12.0-531)$ & $0.116^{\mathrm{a}}$ \\
$\left(10^{3} \times\right.$ copies/ml) & & & \\
\hline
\end{tabular}

Data are median and interquartile range unless stated otherwise. ${ }^{\text {a }}$ Statistical significance determined by Mann-Whitney $\mathrm{U}$ test. ${ }^{\mathrm{b}}$ Statistical significance determined by Pearson's Chi-square tests.
Table 2 The prevalence of IL-23R genotypes in patients undergoing HAART (IRIS) and non-IRIS

\begin{tabular}{llll}
\hline Genotype & IRIS & Non-IRIS & $P$-value \\
\hline rs7530511 & & & \\
CC & $17(70.83)$ & $33(76.74)$ & $0.518^{\text {a }}$ \\
$C T$ & $5(20.83)$ & $9(20.93)$ & \\
$\pi$ & $2(8.33)$ & $1(2.33)$ &
\end{tabular}

\section{rs1884444}

$\begin{array}{llll}\text { GG } & 4(18.18) & 16(39.02) & 0.091^{\mathrm{a}} \\ \mathrm{GT} & 16(72.73) & 18(43.90) & \\ \pi & 2(9.09) & 7(17.07) & \end{array}$

\section{rs11465754}

\begin{tabular}{llll} 
AA & $7(26.92)$ & $16(38.10)$ & $0.426^{\mathrm{a}}$ \\
AG & $16(61.54)$ & $19(45.24)$ & \\
GG & $3(11.54)$ & $7(16.67)$ & \\
rs6682925 & & & \\
CC & $10(38.46)$ & $19(48.72)$ & $0.393^{\mathrm{a}}$ \\
CG & $13(50.00)$ & $13(33.33)$ & \\
GG & $3(11.54)$ & $7(17.95)$ & \\
rs7539625 & & & \\
GG & $5(20.83)$ & $16(36.36)$ & $0.088^{\mathrm{a}}$ \\
GA & $17(70.83)$ & $19(43.18)$ & \\
AA & $2(8.33)$ & $9(20.45)$ & \\
\hline
\end{tabular}

${ }^{a}$ Data are proportions (\%) as determined by Fishers' exact test. The targeted variants were those that had a prevalence of $>10 \%$ in reference African Yoruba population (dbSNP and HAP-MAP). There were no significant differences in proportions of the variants in IRIS versus non-IRIS patients.

( $P=0.715, P=0.863$ ), respectively (data not shown). Taken together, these results demonstrate that the presence of the IL-23R genotypes in cases or controls does not alter CD4 cell counts and HIV loads in this population.

\section{Discussion}

This study investigated the association between five IL23R variants and risk to schistosomiasis-associated IRIS in a Kenyan population naturally exposed to schistosomiasis. We demonstrate that the TT genotype of the rs1884444 ( $\mathrm{T}>\mathrm{G})$ SNP in IL-23R gene was associated with a decreased risk of schistosomiasis-associated IRIS while the four other variant had no association with this disease condition in this western Kenyan population. The rs1884444 is located on exon 2 of IL-23R, and it has been previously shown to be responsible for the signal peptide of IL-23R, since variation in this site may interfere with binding of an exonic splicing enhancer leading to exon skipping, malformation or alternative splicing [40]. In addition, this polymorphism results in amino acid change in codon 3 (His $>$ Gln) and may influence the ligand-receptor specificity and affinity [40], thereby modulating the pro-inflammatory effects of Th17 cell, thus 
Table 3 The association between IL-23R variants and susceptibility to IRIS

\begin{tabular}{|c|c|c|c|}
\hline \multicolumn{4}{|c|}{ IRIS } \\
\hline Genotypes & OR & $95 \% \mathrm{Cl}$ & $P$-value \\
\hline \multicolumn{4}{|l|}{ rs7530511 } \\
\hline CC & 1.00 & & \\
\hline$C T$ & 1.05 & $0.30-3.68$ & 0.308 \\
\hline$\pi$ & 3.64 & $0.30-43.62$ & 0.386 \\
\hline \multicolumn{4}{|l|}{ rs1884444 } \\
\hline GG & 1.00 & & \\
\hline GT & 0.24 & $0.04-1.51$ & 0.129 \\
\hline$\Pi$ & 0.25 & $0.07-0.96$ & 0.043 \\
\hline \multicolumn{4}{|l|}{ rs11465754 } \\
\hline AA & 1.00 & & \\
\hline$A G$ & 0.40 & $0.12-1.33$ & 0.136 \\
\hline GG & 0.37 & $0.07-1.84$ & 0.222 \\
\hline \multicolumn{4}{|l|}{ rs6682925 } \\
\hline CC & 1.00 & & \\
\hline GG & 1.95 & $0.64-5.94$ & 0.240 \\
\hline GG & 0.77 & $0.16-3.81$ & 0.748 \\
\hline \multicolumn{4}{|l|}{ rs7539625 } \\
\hline GG & 1.00 & & \\
\hline GA & 0.34 & $0.10-1.14$ & 0.080 \\
\hline AA & 0.25 & $0.05-1.40$ & 0.116 \\
\hline
\end{tabular}

Data are presented as Odds Ratio (OR) and 95\% Confidence Interval (95\% Cl). Data analyzed by multivariate logistic regression analyses controlling for the confounding effects of age and sex.

$P$-values in bold are significant at $P \leq 0.05$. The reference group in each of the analysis was the most prevalent genotype.

leading to decreased risk to schistosomiasis-associated IRIS. It would be important to carry out a genome-wide study in IRIS-diseased versus non-diseased to fully identify potential genes that may modulate susceptibility to IRIS in populations naturally exposed to schistosomiasis.

Previous studies $[41,42]$ demonstrated that IL-23/IL17 pathway is essential for the development of severe schistosome egg-induced immunopathology and its absence cannot be compensated with other mechanisms. However, the exact molecular mechanism by which IL-23 regulates Th17 cell and the associated activities of the IL-23, IL-23R, and their SNPs and susceptibility to schistosomiasis-associated IRIS are undefined and require further studies. In the current study, we only managed to collect data from a total of 26 well-defined IRIS cases against 45 controls after three months postHAART follow-up. This presented us with a challenge of harnessing enough numbers to effectively carry out detailed functional associations between the SNPs and differential changes in CD4+ cell counts and HIV viral load. Future studies should address the components of large numbers in a well-designed extensive longitudinal survey to fully elucidate the sample size effects over time.

Although previous studies had shown the importance of IL-23 in mediating the development of pathogenic CD4+ T-cell population that produces differential IL-17 (a cytokine associated with higher pathology in schistosomiasis), we found no association between the risk of schistosomiasis-associated IRIS and magnitude of change in CD4+ cell counts or decrease in HIV viral load. Even though surprising, this may be an indication that the rate of immune reconstitution is not an important factor in susceptibility to IRIS $[19,43]$. These findings contrast those of earlier studies, which demonstrated that marked reduction in viral load and magnitude of change in CD4+ cell counts is associated with IRIS risk [44]. The disparity in the current versus previous findings may be partly due to the relative frequency of various IRIS events across the two studies. In the previous studies, IRIS diagnosis was based on consensus expert opinion, and classified by mode of presentation (paradoxical worsening of known opportunistic infection [OI] or unmasking of sub-clinical disease) while in the current study, IRIS was defined as either the re-emergence of symptoms of otherwise successfully treated chronic schistosomiasis on initiation of HAART or the production of schistosome eggs by individuals who were not producing eggs before initiating them on HAART [38]. The symptoms of schistosomiasisassociated IRIS included at least three of the following: hepato-splenomegaly; ultra-sound finding or clinical signs of hypertension; ultra-sound finding or clinical signs of increased granuloma formation/liver fibrosis; haematuria; and egg production in stool (whose presence could not be explained by other possible cause). Such variations in regional definition of disease may lead to differences in both gene and functional associations. It may be plausible to develop regional definition to ascertain whether or not differences exist in disease manifestations.

\section{Conclusion}

In conclusion, we demonstrate for the first time, in this case-control study from a high-risk Kenyan population that the non-synonymous SNP rs1884444 (His3Gln) of IL-23R gene was associated with a decreased risk of schistosomiasis-associated IRIS. However, none of the SNPs were functionally associated with CD4+ cells and HIV viral loads. Further studies incorporating functional evaluations of the IL-23/IL-23R on IL-23R carrier cells in larger cohorts are warranted to validate our findings.

\section{Ethical approval}

The study was approved by the Ethics Review Committee of the Kenya Medical Research Institute. Informed written consent was obtained from all the participants in the study. 


\section{Competing interest}

The authors declare that they have no competing interests.

\section{Authors' contributions}

GOO, CO, ER, WGZOJ, EOM, DK, RC and PNM designed, carried out the survey studies in the population and participated in the drafting of the manuscript. GOO and CO performed the statistical analyses. All authors read and approved the final manuscript.

\section{Acknowledgments}

We are grateful to the study participants and our study team who made this work possible and Director, KEMRI for providing approval to publish this work.

\section{Financial support}

This study was supported by the Neglected Tropical Diseases (NTD) Branch at the Center for Global Health Research (CGHR)-Kenya Medical Research Institute (KEMRI) and the European and Developing Countries Clinical Trials Partnership (EDCTP) senior fellowship to PNM (Mwinzi TA_08_40200_015). This work contributed to GOO's award of MSc degree at Maseno University, Maseno, Kenya.

\section{Author details}

${ }^{1}$ Centre for Global Health Research, Kenya Medical Research Institute, Kisumu, Kenya. ${ }^{2}$ Maseno University, Maseno, Kenya. ${ }^{3}$ Department of Clinical Sciences, Institute of Tropical Medicine, Antwerp, Belgium.

Received: 21 January 2014 Accepted: 29 May 2014

Published: 10 June 2014

\section{References}

1. World AIDS day. East Mediterr Health J 2011, 17(12):901.

2. Murdoch DM, Venter WD, Feldman C, Van Rie A: Incidence and risk factors for the immune reconstitution inflammatory syndrome in HIV patients in South Africa: a prospective study. AIDS 2008, 22(5):601-610.

3. Kumarasamy N, Chaguturu S, Mayer KH, Solomon S, Yepthomi HT, Balakrishnan P, Flanigan TP: Incidence of immune reconstitution syndrome in HIV/tuberculosis-coinfected patients after initiation of generic antiretroviral therapy in India. J Acquir Immune Defic Syndr 2004, 37(5):1574-1576.

4. Smith K, Kuhn L, Coovadia A, Meyers T, Hu CC, Reitz C, Barry G, Strehlau R, Sherman G, Abrams EJ: Immune reconstitution inflammatory syndrome among HIV-infected South African infants initiating antiretroviral therapy. AIDS 2009, 23(9):1097-1107.

5. Shelburne SA, Visnegarwala F, Darcourt J, Graviss EA, Giordano TP, White AC $\mathrm{Jr}$, Hamill RJ: Incidence and risk factors for immune reconstitution inflammatory syndrome during highly active antiretroviral therapy. AIDS 2005, 19(4):399-406.

6. Jevtovic DJ, Salemovic D, Ranin J, Pesic I, Zerjav S, Djurkovic-Djakovic O: The prevalence and risk of immune restoration disease in HIV-infected patients treated with highly active antiretroviral therapy. HIV Med 2005, 6(2):140-143.

7. Lawn SD, Bekker LG, Miller RF: Immune reconstitution disease associated with mycobacterial infections in HIV-infected individuals receiving antiretrovirals. Lancet Infect Dis 2005, 5(6):361-373.

8. Lawn SD, Myer L, Bekker LG, Wood R: Tuberculosis-associated immune reconstitution disease: incidence, risk factors and impact in an antiretroviral treatment service in South Africa. AIDS 2007, 21(3):335-341.

9. Shelburne SA, Montes $M$, Hamill RJ: Immune reconstitution inflammatory syndrome: more answers, more questions. J Antimicrob Chemother 2006, 57(2):167-170.

10. Puthanakit $T$, Oberdorfer $P$, Akarathum N, Wannarit $P$, Sirisanthana $T$, Sirisanthana $V$ : Immune reconstitution syndrome after highly active antiretroviral therapy in human immunodeficiency virus-infected thai children. Pediatr Infect Dis J 2006, 25(1):53-58.

11. Stoll M, Schmidt RE: Adverse events of desirable gain in immunocompetence: the Immune Restoration Inflammatory Syndromes. Autoimmun Rev 2004, 3(4):243-249.

12. Stoll M, Schmidt RE: Immune restoration inflammatory syndromes: apparently paradoxical clinical events after the initiation of HAART. Curr HIV/AIDS Rep 2004, 1(3):122-127.

13. Dhasmana DJ, Dheda K, Ravn P, Wilkinson RJ, Meintjes G: Immune reconstitution inflammatory syndrome in HIV-infected patients receiving antiretroviral therapy: pathogenesis, clinical manifestations and management. Drugs 2008, 68(2):191-208.

14. Haddow LJ, Colebunders R, Meintjes G, Lawn SD, Elliott JH, Manabe YC, Bohjanen PR, Sungkanuparph S, Easterbrook PJ, French MA, Boulware DR, International Network for the Study of HIV-associated IRIS (INSHI): Cryptococcal immune reconstitution inflammatory syndrome in HIV-1-infected individuals: proposed clinical case definitions. Lancet Infect Dis 2010, 10(11):791-802.

15. Lawn SD, Wood R: Immune reconstitution inflammatory syndrome. Lancet Infect Dis 2010, 10(12):833-834.

16. Price $P$, Mathiot N, Krueger R, Stone $S$, Keane NM, French MA: Immune dysfunction and immune restoration disease in HIV patients given highly active antiretroviral therapy. J Clin Virol 2001, 22(3):279-287.

17. Price P, Morahan G, Huang D, Stone E, Cheong KY, Castley A, Rodgers M, Mclntyre MQ, Abraham $\sqcup$, French MA: Polymorphisms in cytokine genes define subpopulations of HIV-1 patients who experienced immune restoration diseases. AIDS 2002, 16(15):2043-2047.

18. Parham C, Chirica M, Timans J, Vaisberg E, Travis M, Cheung J, Pflanz S, Zhang R, Singh KP, Vega F, To W, Wagner J, O'Farrell AM, McClanahan T, Zurawski S, Hannum C, Gorman D, Rennick DM, Kastelein RA, de Waal Malefyt $\mathrm{R}$, Moore KW: A receptor for the heterodimeric cytokine IL-23 is composed of IL-12Rbeta1 and a novel cytokine receptor subunit, IL-23R. $\mathrm{J}$ Immunol 2002, 168(11):5699-5708.

19. Lankford CS, Frucht DM: A unique role for IL-23 in promoting cellular immunity. J Leukoc Biol 2003, 73(1):49-56.

20. Iwakura Y, Nakae S, Saijo S, Ishigame H: The roles of IL-17A in inflammatory immune responses and host defense against pathogens. Immunol Rev 2008, 226:57-79.

21. Romagnani S: Human Th17 cells. Arthritis Res Ther 2008, 10(2):206.

22. Langrish CL, McKenzie BS, Wilson NJ, de Waal Malefyt R, Kastelein RA, Cua DJ: IL-12 and IL-23: master regulators of innate and adaptive immunity. Immunol Rev 2004, 202:96-105.

23. Parkes M, Barrett JC, Prescott NJ, Tremelling M, Anderson CA, Fisher SA, Roberts RG, Nimmo ER, Cummings FR, Soars D, Drummond H, Lees CW, Khawaja SA, Bagnall R, Burke DA, Todhunter CE, Ahmad T, Onnie CM, McArdle W, Strachan D, Bethel G, Bryan C, Lewis CM, Deloukas P, Forbes A, Sanderson J, Jewell DP, Satsangi J, Mansfield JC, Wellcome Trust Case Control Consortium et al: Sequence variants in the autophagy gene IRGM and multiple other replicating loci contribute to Crohn's disease susceptibility. Nat Genet 2007, 39(7):830-832.

24. Cargill M, Schrodi SJ, Chang M, Garcia VE, Brandon R, Callis KP, Matsunami N, Ardlie KG, Civello D, Catanese JJ, Leong DU, Panko JM, McAllister LB, Hansen CB, Papenfuss J, Prescott SM, White TJ, Leppert MF, Krueger GG, Begovich AB: A large-scale genetic association study confirms IL12B and leads to the identification of IL23R as psoriasis-risk genes. Am J Hum Genet 2007, 80(2):273-290.

25. Van Limbergen J, Russell RK, Nimmo ER, Drummond HE, Smith L, Davies G, Anderson NH, Gillett PM, McGrogan P, Hassan K, Weaver L, Bisset WM, Mahdi G, Wilson DC, Satsangi J: IL23R Arg381GIn is associated with childhood onset inflammatory bowel disease in Scotland. Gut 2007, 56(8):1173-1174.

26. Duerr RH, Taylor KD, Brant SR, Rioux JD, Silverberg MS, Daly MJ, Steinhart AH, Abraham C, Regueiro M, Griffiths A, Dassopoulos T, Bitton A, Yang H, Targan S, Datta LW, Kistner EO, Schumm LP, Lee AT, Gregersen PK, Barmada MM, Rotter Jl, Nicolae DL, Cho JH: A genome-wide association study identifies IL23R as an inflammatory bowel disease gene. Science 2006, 314(5804):1461-1463.

27. Huffmeier U, Lascorz J, Bohm B, Lohmann J, Wendler J, Mossner R, Reich K, Traupe H, Kurrat W, Burkhardt H, Reis A: Genetic variants of the IL-23R pathway: association with psoriatic arthritis and psoriasis vulgaris, but no specific risk factor for arthritis. J Invest Dermatol 2009, 129(2):355-358.

28. Ouma C, Davenport GC, Awandare GA, Keller CC, Were T, Otieno MF, Vulule JM, Martinson J, Ong'echa JM, Ferrell RE, Perkins DJ: Polymorphic variability in the interleukin (IL)-1beta promoter conditions susceptibility to severe malarial anemia and functional changes in IL-1 beta production. J Infect Dis 2008, 198(8):1219-1226

29. Ouma C, Keller CC, Davenport GC, Were T, Konah S, Otieno MF, Hittner JB, Vulule JM, Martinson J, Ong'echa JM, Ferrell RE, Perkins DJ: A novel functional variant in the stem cell growth factor promoter protects against severe malarial anemia. Infect Immun 2010, 78(1):453-460.

30. Haase AT: Perils at mucosal front lines for HIV and SIV and their hosts. Nat Rev Immunol 2005, 5(10):783-792. 
31. Jurriaans S, Van Gemen B, Weverling GJ, Van Strijp D, Nara P, Coutinho R, Koot M, Schuitemaker H, Goudsmit J: The natural history of HIV-1 infection: virus load and virus phenotype independent determinants of clinical course? Virology 1994, 204(1):223-233.

32. Yates A, Stark J, Klein N, Antia R, Callard R: Understanding the slow depletion of memory CD4+ T cells in HIV infection. PLoS Med 2007, 4(5):e177.

33. Karanja DM, Boyer AE, Strand M, Colley DG, Nahlen BL, Ouma JH, Secor WE: Studies on schistosomiasis in western Kenya: II. Efficacy of praziquantel for treatment of schistosomiasis in persons coinfected with human immunodeficiency virus-1. Am J Trop Med Hyg 1998, 59(2):307-311.

34. Karanja DM, Colley DG, Nahlen BL, Ouma JH, Secor WE: Studies on schistosomiasis in western Kenya: I. Evidence for immune-facilitated excretion of schistosome eggs from patients with Schistosoma mansoni and human immunodeficiency virus coinfections. Am J Trop Med Hyg 1997, 56(5):515-521.

35. Mwinzi PN, Karanja DM, Colley DG, Orago AS, Secor WE: Cellular immune responses of schistosomiasis patients are altered by human immunodeficiency virus type 1 coinfection. J Infect Dis 2001, 184(4):488-496.

36. Watanabe K, Mwinzi PN, Black CL, Muok EM, Karanja DM, Secor WE, Colley DG: T regulatory cell levels decrease in people infected with Schistosoma mansoni on effective treatment. Am J Trop Med Hyg 2007, 77(4):676-682.

37. Peters PA, El Alamy M, Warren KS, Mahmoud AA: Quick Kato smear for field quantification of Schistosoma mansoni eggs. Am J Trop Med Hyg 1980, 29(2):217-219.

38. de Silva S, Walsh J, Brown M: Symptomatic Schistosoma mansoni infection as an immune restoration phenomenon in a patient receiving antiretroviral therapy. Clin Infect Dis 2006, 42(2):303-304.

39. Pietschmann P, Gollob E, Brosch S, Hahn P, Kudlacek S, Willheim M, Woloszczuk W, Peterlik M, Tragl KH: The effect of age and gender on cytokine production by human peripheral blood mononuclear cells and markers of bone metabolism. Exp Gerontol 2003, 38(10):1119-1127.

40. Kan SH, Mancini G, Gallagher G: Identification and characterization of multiple splice forms of the human interleukin-23 receptor alpha chain in mitogen-activated leukocytes. Genes Immun 2008, 9(7):631-639.

41. Rutitzky LI, Bazzone L, Shainheit MG, Joyce-Shaikh B, Cua DJ, Stadecker MJ: IL-23 is required for the development of severe egg-induced immunopathology in schistosomiasis and for lesional expression of IL-17. J Immunol 2008, 180(4):2486-2495.

42. Rutitzky LI, Stadecker MJ: CD4 T cells producing pro-inflammatory interleukin-17 mediate high pathology in schistosomiasis. Mem Inst Oswaldo Cruz 2006, 101(Suppl 1):327-330.

43. Smith PM, Shainheit MG, Bazzone LE, Rutitzky LI, Poltorak A, Stadecker MJ: Genetic control of severe egg-induced immunopathology and IL-17 production in murine schistosomiasis. J Immunol 2009, 183(5):3317-3323.

44. Haddow LI, Moosa MY, Mosam A, Moodley P, Parboosing R, Easterbrook PJ: Incidence, clinical spectrum, risk factors and impact of HIV-associated immune reconstitution inflammatory syndrome in South Africa. PLoS One 2012, 7(11):e40623.

doi:10.1186/1471-2334-14-316

Cite this article as: Ogola et al:: A non-synonymous polymorphism in IL-23R Gene ( $r$ 1884444) is associated with reduced risk to schistosomiasisassociated Immune Reconstitution Inflammatory Syndrome in a Kenyan population. BMC Infectious Diseases 2014 14:316.

\section{Submit your next manuscript to BioMed Central and take full advantage of:}

- Convenient online submission

- Thorough peer review

- No space constraints or color figure charges

- Immediate publication on acceptance

- Inclusion in PubMed, CAS, Scopus and Google Scholar

- Research which is freely available for redistribution

Submit your manuscript at www.biomedcentral.com/submit
C Biomed Central 